\title{
Design and performance testing of a novel emergency ventilator for in-hospital use
}

\author{
Jacob M. Knorr B.S. ${ }^{* 1}$, Megan M. Sheehan B.S. ${ }^{* 1}$, Daniel C. Santana B.A. ${ }^{* 1}$, Sergey Samorezov MSME², \\ Ibrahim Sammour MD FAAP CHSE ${ }^{3}$, Michael Deblock PhD ${ }^{4}$, Barry Kuban BSEE , Neal Chaisson MD ${ }^{5}$, \\ Robert L. Chatburn MHHS RRT-NPS FAARC ${ }^{6}$
}

\begin{abstract}
JM Knorr, MM Sheehan, DC Santana, S Samorezov, I Sammour, M Deblock, B Kuban, N Chaisson, RL Chatburn. Design and performance testing of a novel emergency ventilator for in-hospital use. Can J Respir Ther 2020;56:42-51. doi: 10.29390/cjrt-2020-023.
\end{abstract}

\begin{abstract}
Background: The rapidly evolving COVID-19 pandemic has led to increased use of critical care resources, particularly mechanical ventilators. Amidst growing concerns that the health care system could face a shortage of ventilators in the future, there is a need for an affordable, simple, easy to use, emergency stockpile ventilator.

Methods: Our team of engineers and clinicians designed and tested an emergency ventilator that uses a single limb portable ventilator circuit. The circuit is controlled by a pneumatic signal with electronic microcontroller input, using air and oxygen sources found in standard patient rooms. Ventilator performance was assessed using an IngMar ASL 5000 breathing simulator, and it was compared with a commercially available mechanical ventilator.

Results: The emergency ventilator provides volume control mode, intermittent mandatory ventilation and continuous positive airway pressure. It can generate tidal volumes between 300 and $800 \mathrm{~mL}$ with $<10 \%$ error, with pressure, volume, and waveforms substantially equivalent to existing commercial ventilators.

Conclusions: We describe a cost effective, safe, and easy to use ventilator that can be rapidly manufactured to address ventilator shortages in a pandemic setting. It meets basic clinical needs and can be provided for emergency use in cases requiring mechanical ventilation because of complications due to respiratory failure from infectious diseases.
\end{abstract}

Key Words: mechanical ventilator; emergency use ventilator; ventilator shortage; stockpile; COVID-19; pandemic

\section{INTRODUCTION}

The emerging COVID-19 pandemic has spread globally to include over $19,400,000$ reported cases and 722,000 deaths as of 9 August 2020 [1]. A common complication of COVID-19 infection is bilateral pneumonia, which may progress to acute respiratory distress syndrome (ARDS). Initial studies of infected patients show that development of ARDS contributes significantly to escalation of care and mortality risk [2, 3]. Early studies from China indicate that approximately $5.0 \%$ of patients affected by COVID-19 will require intensive care, and $2.3 \%$ will require invasive mechanical ventilation [4], though publication and underreporting bias suggest these numbers could be significantly higher [5].

As the number of cases grew across the world in March, April, and May of 2020, there was an unprecedented strain placed on the health care systems of many countries. National ventilator stockpiles and qualified personnel to run them were depleted as these resources were mobilized to address surges in critically ill patients with COVID-19. Accordingly, select health care systems in areas such as New York City, northern Italy, and Brazil had been forced to ration critical care beds and ventilators [6]. Several strategies have been proposed to address a shortage in mechanical ventilators. These include inexpensive devices that use an electronically controlled actuator to deliver a breath via bag valve mask (BVM) [7] and devices that regulate pressure of compressed medical air using water columns and pneumatic valves [8]. Alternative solutions include the use of one ventilator for up to four patients, which has been widely discouraged by the American Association for Respiratory Care and other societies due to poor outcomes $[9,10]$. However, many of these strategies are designed for temporary stabilization until a standard ventilator becomes available. Early studies have shown that patients with COVID-19 require prolonged ventilation over days to weeks, indicating that a more robust solution is needed in the event of a future COVID-19 wave or other mass casualty scenario [11].

As an alternative, we introduce a novel design for a simple, low-cost, easy to operate emergency use ventilator (EUV) that can be mass produced to address future shortages for the treatment of patients with ARDS due to pandemic viral illness. The purpose of this study was to determine the performance characteristics of this device to determine if it would meet the needs of patients affected by COVID-19 and other respiratory illness.

\footnotetext{
*Denotes shared first-authorship.

${ }^{1}$ Cleveland Clinic Lerner College of Medicine, Cleveland Clinic Foundation, Cleveland, OH;

${ }^{2}$ Department of Biomedical Engineering, Lerner Research Institute, Cleveland Clinic Foundation, Cleveland, OH;

${ }^{3}$ Department of Neonatology, Cleveland Clinic Children's, Cleveland Clinic Foundation, Cleveland, OH;

${ }^{4}$ Electronics Core, Lerner Research Institute, Cleveland Clinic Foundation, Cleveland, OH;

${ }^{5}$ Department of Pulmonary Medicine, Cleveland Clinic Foundation, Cleveland, $\mathrm{OH}$;

${ }^{6}$ Respiratory Services Institute, Cleveland Clinic Foundation, Cleveland, $\mathrm{OH}$

Correspondence: Jacob M. Knorr, 9500 Euclid Ave, Cleveland, OH 44195. Tel.: 937-470-8075. E-mail: knorrj@ccf.org
}

Published online at https://www.cjrt.ca on 28 September 2020 


\section{DEVICE DESIGN}

Clinical needs and considerations

Our EUV was designed with specific clinical and practical goals in mind. Desirable features of the device are listed in Table 1 as determined by clinical and environmental constraints identified by our team of clinicians, respiratory therapists, and engineers. Our practical goal was to design a ventilator with components common to the medical gas/ electronics industries that could be easily and inexpensively sourced without custom manufacturing (i.e., no 3-D printing or custom machining required) for $>$ US $\$ 500$. We established minimum performance criteria (Table 2) for a ventilator from American Association of Respiratory Care guidelines [12] and followed guidance for additional performance features, including safety alarm and pressure relief valve, published by the UK Medicines \& Healthcare products Regulator Agency [13] and the Association for Advancing Medical Instrumentation [14].

To reduce cost and complexity, we made control of flow and fraction of inspired oxygen $\left(\mathrm{FiO}_{2}\right)$ dependent on standard medical air and oxygen flowmeters, rather than incorporating those functions within the ventilator. We also specified the ventilator to operate in one mode (volume control mode).

Our clinical goal was to design a ventilator that was attentive to manpower shortages that often accompany disasters such as COVID-19. The design is intended for operators with little or no experience with mechanical ventilation. Thus, we only provide a single mode, which prioritizes patient safety over comfort $[14,15]$. Volume control (VC) modes are still the most commonly used worldwide, are simple to understand and use, and can help to achieve the low tidal volumes recommended for ventilation in the setting of ARDS due to COVID-19 [16], particularly with patients whose respiratory system compliance may change dramatically over the course of care. To provide variable support, (i.e., to provide a range from total support to gradual weaning to continuous positive airway pressure (CPAP) only), we implemented an intermittent mandatory ventilation (IMV) breath sequence with set-point targeting for both mandatory and spontaneous breaths (VC-IMVs,s) [17]. IMV, rather than synchronized IMV (SIMV), is not very common today, but was the most common breath sequence for both infants and adults starting in the 1970s and up to the introduction of microcontrollers in computer design in the late 1980s [18]. The advantage of IMV instead of SIMV is that it greatly simplifies design complexity. The disadvantage of IMV is that without synchronization of mandatory breaths with the patient's inspiratory effort, the risk of patient-ventilator asynchrony increases (i.e., early or late triggering) [19]. Despite this disadvantage, IMV was chosen particularly as patients with severe ARDS are often highly

\section{TABLE 1}

\section{Desired design features}

Input criteria Pneumatic: medical flowmeters attached to 50 psig source connected to ventilator with high pressure hoses Air: inspiratory flow and bias flow; control signal for exhalation manifold

Oxygen: inspiratory flow and bias flow

Electrical: power for exhalation manifold control circuit

Output criteria Adjustable $\mathrm{FiO}_{2}$

Adjustable breath rate and inspiratory time

Adjustable PEEP

Adjustable tidal volume

Disposable single-limb patient circuit

Control circuit Electrical control of pneumatic pulse train to exhalation manifold

Digital display of

- inspiratory time

- breath rate

- peak airway pressure

- PEEP

Safety features

- disconnect alarm

- high pressure alarm

- electrical failure alarm sedated and chemically paralyzed for a large portion of the duration of ventilation. For these reasons, synchronization with, or assistance for, spontaneous breaths (i.e., pressure support) was excluded.

\section{Design overview}

Figure 1a shows a schematic of the ventilator. We designed the ventilator to operate with a common, disposable, single limb patient circuit (Vyaire \#001795). Supplemental Figure $1^{1}$ displays the full ventilator when attached to wall air fixtures and single limb circuit with test lung. The device weighed $4 \mathrm{~kg}$ and measured $8 \mathrm{~cm} \times 30 \mathrm{~cm} \times 40 \mathrm{~cm}$ as tested, allowing for use on a bedside table or movable stand. The exhalation manifold of the circuit included a pneumatic control system to apply a pressure signal to the pneumatic diaphragm of the manifold. In this way, the valve of the exhalation manifold could be closed to allow inspiration and partially opened to allow expiration and regulate positive end expiratory pressure (PEEP) at a user set breath rate and inspiratory time (Figure 1b). Flow to the inspiratory circuit is regulated by external medical air and oxygen flowmeters. Adjustment of the flow from the air and oxygen flowmeters provides control of both tidal volume and $\mathrm{FiO}_{2}$. These flowmeters are back-pressure compensated, meaning inspiratory flow is unaffected by back pressure generated during ventilation. Nomograms were designed to facilitate these settings (Supplemental Figure $2^{1}$ ) and were mounted on the top of the ventilator. The equations used to create the nomograms are given in the Supplemental Material ${ }^{1}$. Humidification can be supplied using standard heated or passive systems as needed, and the expiratory outlet to the single limb circuit can incorporate an N100 filter to prevent aerosolization of viral particles.

\section{Electronic circuit}

We used a microcontroller (Arduino Nano 3 (ATmega328 microcontroller), Figure 2) to generate an electronic pulse train signal that controls the breath rate and inspiratory time. The microcontroller actuates a solenoid valve in the pneumatic signal circuit, which connects to the exhalation manifold. The microcontroller accepts user inputs via two potentiometers to control breath rate and inspiratory time. Two push buttons were implemented to allow the user to select the ventilator mode (CPAP or VC-IMV) and lock or unlock the potentiometer knobs from changing breath rate and inspiratory time.

We included a pressure sensor (Honeywell MPRLS0001PG0000SAB) to detect patient airway pressures, at a sampling rate of 20 readings per second. During one full inspiratory-expiratory cycle (one breath), the maximum pressure reading detected was taken and displayed as the peak inspiratory pressure (PIP), while minimum pressure recorded was taken and displayed as the PEEP. A 4-line, 20-character LCD screen on the front panel of the ventilator was used to display the breath rate, inspiratory time, settings lock status, current airway pressure, PIP, and PEEP.

Using pressure readings and a $5 \mathrm{~V}$ DC buzzer, various alarm features were implemented. If the airway pressure exceeded $70 \mathrm{~cm} \mathrm{H}_{2} \mathrm{O}$, the microcontroller activated the buzzer to generate an audible alarm and automatically cycled off inspiration. If the airway pressure dropped below $3 \mathrm{~cm} \mathrm{H} \mathrm{H}_{2} \mathrm{O}$ for at least $200 \mathrm{~ms}$, this was taken to indicate circuit disconnect, and an audible alarm was activated until a button was pressed or airway pressures exceeded $3 \mathrm{~cm} \mathrm{H}_{2} \mathrm{O}$. Ventilator triggering and cycling continued in this low-pressure scenario and false triggering was not observed in the setting of simulated patient effort.

A standard $120 \mathrm{~V}$ AC to $12 \mathrm{~V} \mathrm{DC}$ converter with 2 amps of current was used to power the electronic circuit. A $12 \mathrm{~V}$ to $5 \mathrm{~V}$ voltage regulator (IC 7805) was used to deliver $5 \mathrm{~V}$ to the microcontroller per its specification. A $5 \mathrm{~V}$ to $3.3 \mathrm{~V}$ logic level converter (SparkFun BSS138) was used to deliver $3.3 \mathrm{~V}$ to the pressure sensor per its specification.

We created a power disconnect alarm using a $12 \mathrm{~V}$ relay and an 8-12 V DC buzzer with a $9 \mathrm{~V}$ battery. If the power to the ventilator was

\footnotetext{
${ }^{1}$ Supplementary data are available with the article through the journal Web site at https://www.cjrt.ca/wp-content/uploads/Supplemental-informationCJRT-2020-23.docx.
} 


\section{TABLE 2}

\section{Required performance criteria}

\begin{tabular}{|c|c|c|c|}
\hline & Range & Accuracy & Settings \\
\hline Tidal volume & 0-800 mL & $\pm 50 \mathrm{~mL}$ or $<10 \%$ & Result of flow and inspiratory time settings \\
\hline Respiratory rate & $8-30 \mathrm{bpm}$ & \pm negligible & Continuous knob adjustment \\
\hline Inspiratory time & $0-2 \mathrm{~s}$ & Assessed by tidal volume accuracy & Continuous knob adjustment \\
\hline Peep valve & $3-30 \mathrm{~cm} \mathrm{H}_{2} \mathrm{O}$ & $\pm 0.5 \mathrm{~cm} \mathrm{H}_{2} \mathrm{O}$ & Continuous knob adjustment \\
\hline High pressure valve & $60 \mathrm{~cm} \mathrm{H}_{2} \mathrm{O}$ & $\pm 0.5 \mathrm{~cm} \mathrm{H}_{2} \mathrm{O}$ & Preset \\
\hline $\mathrm{FiO}_{2}$ & $40 \%-100 \%$ & $\pm 5 \%$ & Result of air and oxygen flowmeter settings \\
\hline High pressure sensor + shutoff & $>70 \mathrm{~cm} \mathrm{H}_{2} \mathrm{O}$ & $\pm 2 \mathrm{~cm} \mathrm{H}_{2} \mathrm{O}$ & Preset in software \\
\hline Low pressure sensor & $<3 \mathrm{~cm} \mathrm{H}_{2} \mathrm{O}$ & $\pm 1 \mathrm{~cm} \mathrm{H} \mathrm{H}_{2} \mathrm{O}$ & Preset in software \\
\hline Oxygen flow & $0-15 \mathrm{~L} / \mathrm{min}$ & Assessed by tidal volume and $\mathrm{FiO}_{2}$ accuracy & Continuously adjustable \\
\hline Air flow & $0-15 \mathrm{~L} / \mathrm{min}$ & Assessed by tidal volume and $\mathrm{FiO}_{2}$ accuracy & Continuously adjustable \\
\hline
\end{tabular}

\section{FIGURE 1}

Device schematic and front panel. (a) Emergency ventilator components: single-limb ventilator circuit, electrical microcontroller, solenoid valve, positive end-expiratory pressure flow resistor, peak inspiratory pressure flow resistor, and flowmeters. (b) The user interface consists of push button controls for stopping and starting ventilation and locking settings, as well as analog knobs for breath rate and inspiratory time adjustment. Feedback is provided to the user via LCD which displays real time pressure (P0), PIP, and PEEP. On the right of the panel are connections to the inspiratory circuit, exhalation manifold, and airway pressure connection.

a.

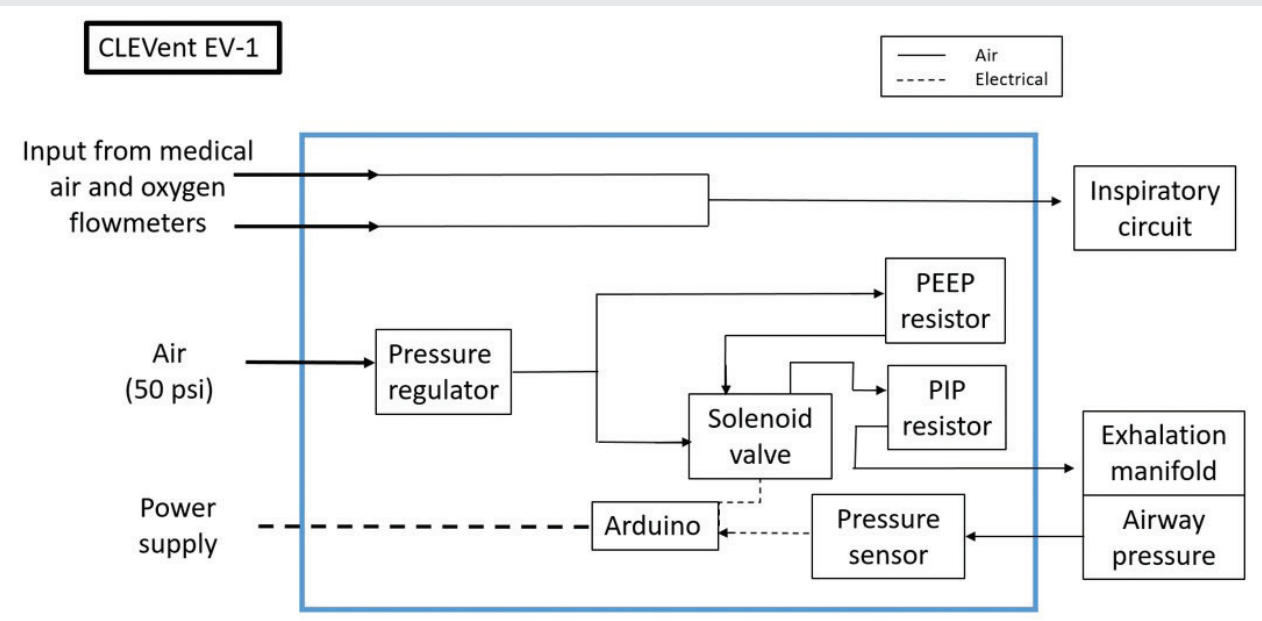

b.

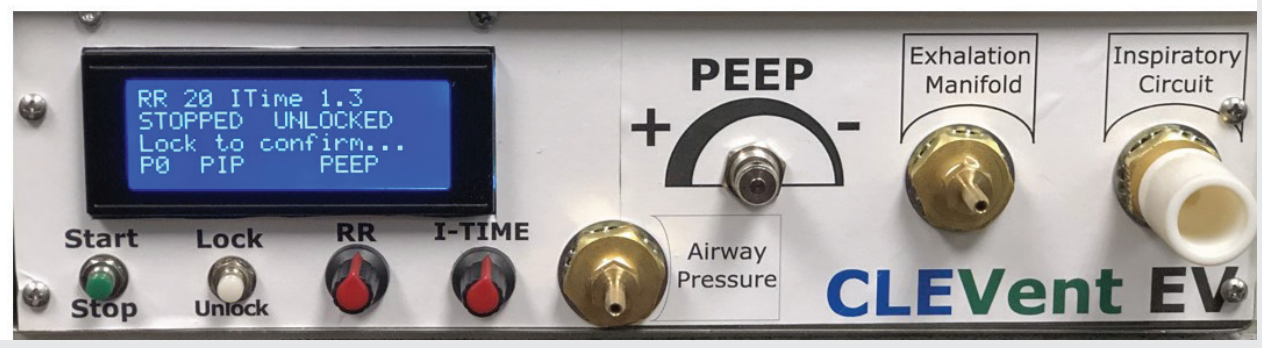

disconnected while turned on, the relay would trigger current flow to the buzzer from the $9 \mathrm{~V}$ battery. An alarm silence switch was implemented on the back of the ventilator to turn off this alarm in the case of intentional power disconnect.

Pneumatic exhalation manifold circuit

To control the exhalation manifold, we designed a circuit that generates a rectangular pressure signal with adjustable frequency and duty cycle (corresponding to the user controls of breath rate and inspiratory time, respectively) as shown in Figure 3. Design considerations included compatibility with an electronically controlled solenoid valve and minimizing the effect of intrinsic flow resistance of individual components. The final circuit chosen for implementation uses air at 1.0 pounds per square in gauge (psig) applied to an electronically controlled solenoid valve. When not powered, the valve is closed, and air flow is directed through a flow resistor. The pressure across this 


\section{FIGURE 2}

Electronic circuit diagram. Electrical schematic of microcontroller circuit. The logic level converter connects to the Honeywell pressure sensor using standard SPI connections as labeled. The LCD backpack connects to the LCD display using standard I2C connections as labeled.

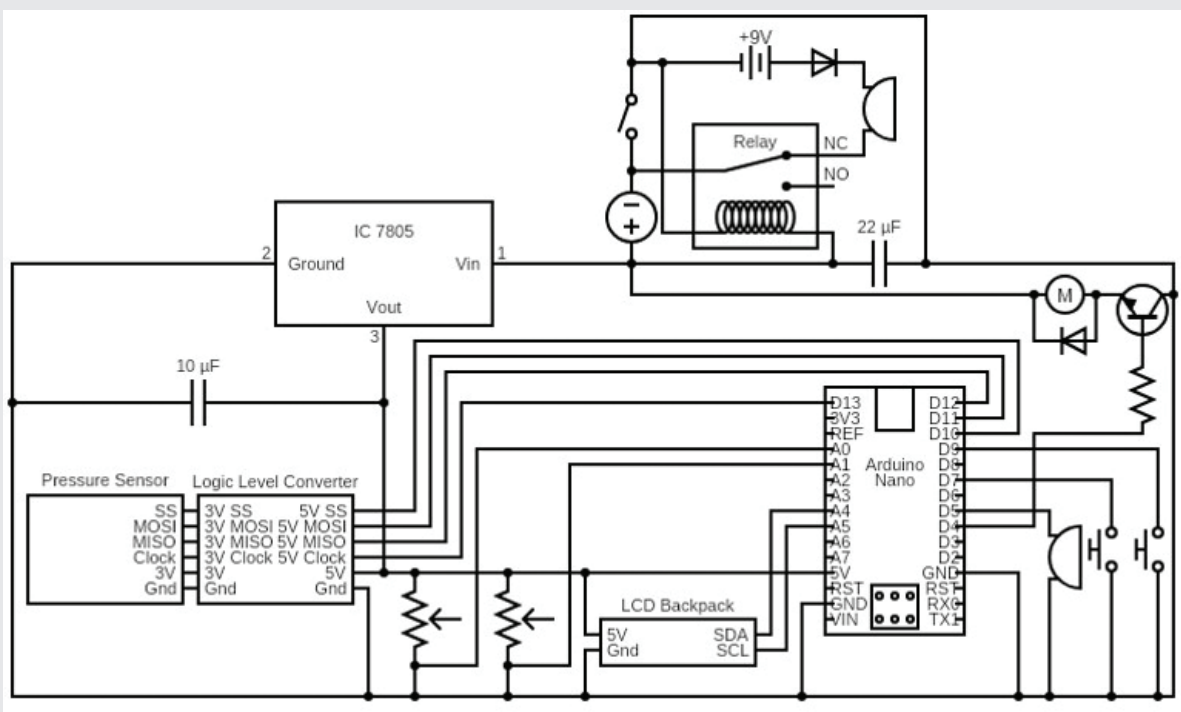

\section{FIGURE 3}

Pneumatic circuit diagram. Pneumatic circuits to control exhalation valve. Part (a) is the expiratory pneumatic circuit, with outputs to the exhalation manifold. Part (b) is the inspiratory circuit, which includes a pressure relief valve for added safety within the device.

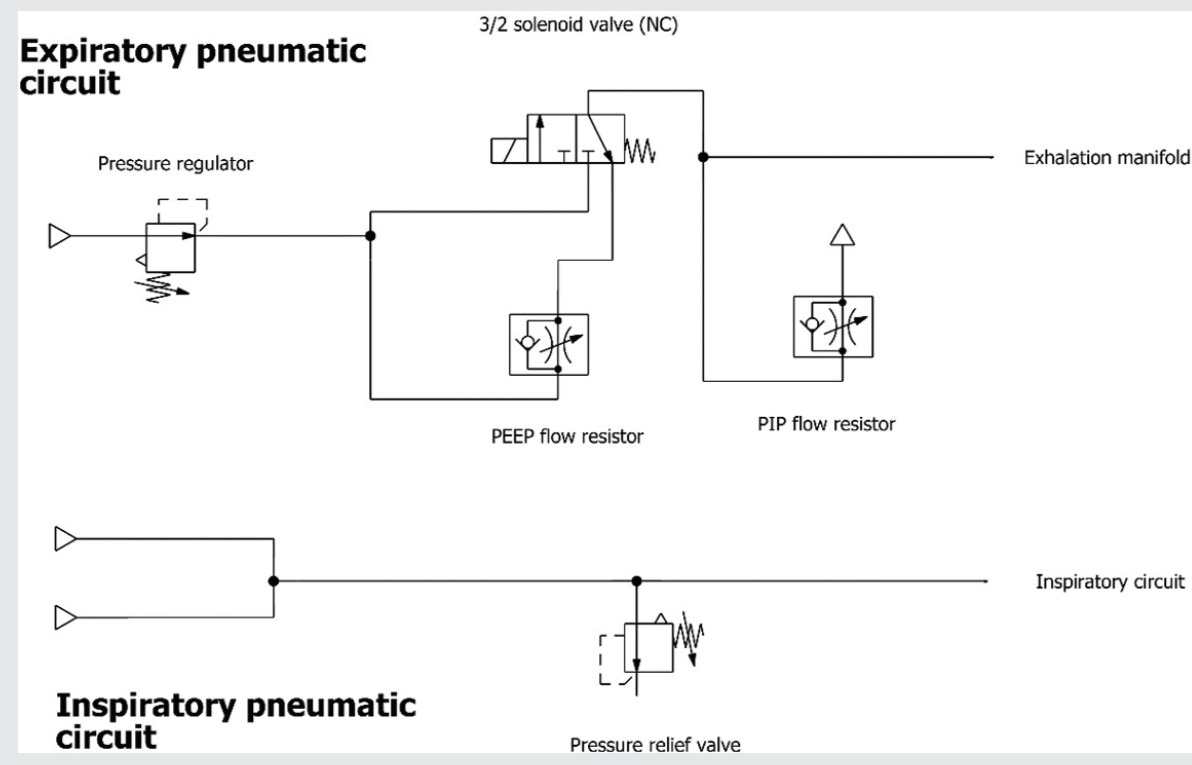

resistor is used to generate a PEEP control signal to the exhalation manifold. This value can be adjusted by the operator by means of a rotary mechanical knob on the front panel of the ventilator. When the solenoid valve is activated and opened by a signal from the microcontroller, the low-pressure (PEEP) flow resistor is bypassed and flow is directed through the high-pressure (inspiratory pressure) flow resistor. The high-pressure signal closes the exhalation manifold to initiate the inspiratory period of the cycle. PIP is set internally to 60 $\mathrm{cm} \mathrm{H}_{2} \mathrm{O}$, with a mechanical pressure relief valve, for safety (Figure 3). During normal operation, PIP is dependent on inspiratory flow, tidal volume, and respiratory system mechanical properties, as is characteristic of volume control ventilation modes. 


\section{Device operation}

To operate the ventilator, one standard medical air and one medical oxygen flowmeter are connected to respective supply outlets (50 psig). The flowmeters are attached to the ventilator using medical-grade high-pressure hose. Another high-pressure hose connects an additional wall-air outlet at $50 \mathrm{psi}$ to the ventilator, which is reduced to $1.0 \mathrm{psi}$ by a regulator inside the ventilator and drives the pneumatic signal generator controlling the exhalation valve. The single limb ventilator circuit is attached to the front of the unit and the unit is plugged into $120 \mathrm{~V} \mathrm{AC}$ electrical power.

A power switch at the back of the ventilator turns the device on, as indicated by the LCD screen display. Desired total flow and $\mathrm{FiO}_{2}$ is set and the patient limb circuit is attached to the endotracheal or tracheostomy tube. When turned on, the default mode for the device is CPAP (i.e., breath rate $=0$ ). The PEEP can be adjusted by rotating the corresponding control knob to the desired level. PEEP is displayed on the LCD screen. Before starting ventilation, the desired inspiratory time and breath rate are selected via knobs attached to potentiometers. The set values for breath rate and inspiratory time along with measured values for PIP and PEEP are displayed on the screen of the front panel (Figure 1b). The LOCK/UNLOCK button is then pressed to confirm and lock the desired settings, and the START/STOP button is pressed to initiate ventilation. Breath rate and inspiratory time can be changed at any time by depressing the LOCK/UNLOCK button, setting knob inputs, and initiating these settings by depressing the LOCK/UNLOCK button again. PEEP can be adjusted at any time during ventilation without depressing the LOCK/UNLOCK button. To stop ventilation, the START/STOP button on the front of the device is pressed, returning the device to CPAP mode.

\section{METHODS}

\section{Performance characterization and validation}

The performance of this system was evaluated using an ASL 5000 breathing simulator (IngMar Medical, Pittsburgh, PA) with software version 3.6. The primary purpose of the testing was to establish the range of tidal volume, inspiratory time, and breath rate delivered by the ventilator using a passive lung model. A secondary purpose was to compare the performance of the prototype ventilator with a commercial ventilator set to the same mode with a passive and an active lung model (i.e., with simulated inspiratory effort). All ASL 5000 testing protocols were created de novo to interrogate ventilator performance characteristics in specific clinical scenarios.

The delivered tidal volume was calculated by estimating the volume of gas compressed in the patient circuit during inspiration and subtracting it from the set tidal volume:

delivered $\mathrm{V}_{\mathrm{T}}=$ set $\mathrm{V}_{\mathrm{T}}-$ compressed volume

and

compressed volume $=(\mathrm{PIP}-\mathrm{PEEP}) \times \mathrm{C}_{\mathrm{PC}}$

where $V_{T}$ is tidal volume, PIP is peak inspiratory pressure during mechanical ventilation, PEEPis positive end expiratory pressure, and $\mathrm{C}_{\mathrm{PC}}$ is the compliance of the patient circuit.

To determine $\mathrm{C}_{\mathrm{PC}}$, the total flow to the ventilator was set to $6 \mathrm{~L} / \mathrm{min}$, the inspiratory time was set to $1 \mathrm{~s}$, and PEEP was set to $5 \mathrm{~cm} \mathrm{H}_{2} \mathrm{O}$. The volume injected into the patient circuit with these settings was $100 \mathrm{~mL}$ $(6 \mathrm{~L} / \mathrm{min}$ is $100 \mathrm{~mL} / \mathrm{s})$. With the patient connection port occluded, the PIP and PEEP were recorded from the emergency ventilator's LCD screen. $\mathrm{C}_{\mathrm{PC}}$ was calculated as follows.

$\mathrm{C}_{\mathrm{PC}}=100 \mathrm{~mL} /(\mathrm{PIP}-\mathrm{PEEP})$

A typical value for $\mathrm{C}_{\mathrm{PC}}$ with the circuit we used was $2.1 \mathrm{~mL} / \mathrm{cm} \mathrm{H}_{2} \mathrm{O}$. We performed these corrections because they estimate tidal volume assuming atmospheric temperature and pressure dry conditions (ATPD) (dry gas at ambient temperature and pressure) conditions, whereas delivered gas will reach the patient under body temperature and pressure saturated (BTPS) conditions.

\section{Simulation models}

The ASL 5000 breathing simulator allows construction of lung models (simulated respiratory system resistance $(\mathrm{R})$ and compliance $(\mathrm{C})$ that are paired with effort models. Effort models represent simulated inspiratory effort in terms of the parameters of a muscle pressure (Pmus) waveform. These parameters include breath rate, maximum effort, maximum pressure (Pmax), inspiratory effort rise time, and effort relaxation time (times are expressed as a percent of the ventilatory period, $1 /$ rate).

Ventilator performance characterization data were obtained using a passive lung model representing mild to severe ARDS; $\mathrm{R}=10 \mathrm{~cm}$ $\mathrm{H}_{2} \mathrm{O} / \mathrm{L} / \mathrm{s}$ and $\mathrm{C}=20-50 \mathrm{~mL} / \mathrm{cm} \mathrm{H}_{2} \mathrm{O}[20]$.

The initial lung compliance was set at $50 \mathrm{~mL} / \mathrm{cm} \mathrm{H}_{2} \mathrm{O}$, and then decreased in a stepwise fashion in $10 \mathrm{~mL} / \mathrm{cm} \mathrm{H}_{2} \mathrm{O}$ increments to a minimum of $20 \mathrm{~mL} / \mathrm{cm} \mathrm{H}_{2} \mathrm{O}$, after which it returned incrementally to the baseline compliance of $50 \mathrm{~mL} / \mathrm{cm} \mathrm{H}_{2} \mathrm{O}$.

Comparison of the prototype ventilator with a commercial ventilator (Puritan Bennet PB840) was performed with both the passive models

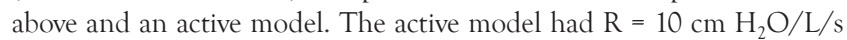
and $\mathrm{C}=40 \mathrm{~mL} / \mathrm{cm} \mathrm{H}_{2} \mathrm{O}$ plus a sinusoidal half-wave effort model of: frequency $(\mathrm{f})=18$ breathes per minute $(\mathrm{bpm}), \mathrm{Pmax}=-5 \mathrm{~cm} \mathrm{H}_{2} \mathrm{O}, \%$ increase $=15, \%$ hold $=0, \%$ release $=15$. The total generated Pmus inspiratory time was $1 \mathrm{~s}$.

\section{Test protocol}

All testing was performed without a humidifier. Initial performance testing was conducted with a version of the tidal volume nomogram that assumed ATPD as this is how gas is delivered by the ventilator. Atmospheric temperature was $67.5^{\circ} \mathrm{F}$.

Pressure, volume, and flow waveforms were recorded by the simulator at a sampling rate of $512 \mathrm{~Hz}$ and gas conditions set initially to "as measured" (i.e., not corrected for body temperature and pressure saturated with water vapor (BTPS) conditions). To compare the accuracy of delivered tidal volume using the calculation method versus what would be delivered under BTPS conditions, we subsequently reanalyzed the delivered tidal volume under BTPS conditions using post-test analysis. Mean values from at least 10 breaths are reported. Standard deviation was not recorded because this type of simulation yields measurements with negligible variance breath to breath.

The pressure sensor attached to the circuit was used as is with manufacturer calibration, and calibration was confirmed prior to device testing.

\section{Establishing inspiratory time correction}

Given the pneumatic nature of the drive train, we determined that the set solenoid on-time may not equal the desired inspiratory time $\left(\mathrm{T}_{\mathrm{I}}\right)$. Thus, to allow for accurate determination of $\mathrm{T}_{\mathrm{I}}$, the system might require calibration. Calibration was achieved by adjusting the solenoid on-time on the prototype ventilator incrementally from $0.65 \mathrm{~s}$ to $2.0 \mathrm{~s}$, while the actual $\mathrm{T}_{\mathrm{I}}$ was measured with the ASL 5000. The ventilator settings used were a set flow of $30 \mathrm{~L} / \mathrm{min}$ and a PEEP of $\sim 5 \mathrm{~cm} \mathrm{H} \mathrm{H}_{2} \mathrm{O}$ as displayed by the ventilator's LCD screen. A linear regression was performed (Supplemental Figure $3^{1}$ ), and a correction equation was derived as:

measured $T_{I}=\left(0.9069 \times \operatorname{expected} T_{I}\right)+0.2882$

The correction was implemented into our software to better reflect the desired $T_{1}$. Of note, we anticipate these corrections will be device specific due to the influence of minute changes in input pressure and flow resistor position.

\section{Ventilator settings for performance characterization}

Using two total flow rates of $20 \mathrm{~L} / \mathrm{min}\left(10 \mathrm{~L} / \mathrm{min} \mathrm{O}_{2}, 10 \mathrm{~L} / \mathrm{min}\right.$ air $)$ and $30 \mathrm{~L} / \min \left(15 \mathrm{~L} / \mathrm{min}_{2}, 15 \mathrm{~L} / \mathrm{min}\right.$ air $)$, and a set breath rate of $15 \mathrm{bpm}$, the inspiratory time was incrementally increased from $0.8 \mathrm{~s}$ to $2 \mathrm{~s}$. 
The values for set $\mathrm{V}_{\mathrm{T}}$ (by the nomogram), were compared with those corrected using Equation 1 and those measured by the simulator, delivered $V_{T}$ at ATPD and BTPS conditions. The error in volume delivery was calculated as:

Error $=\left(\left(\right.\right.$ set $\mathrm{V}_{\mathrm{T}}-$ measured $\left.\mathrm{V}_{\mathrm{T}}\right) /$ set $\left.\mathrm{V}_{\mathrm{T}}\right) \times 100 \%$

\section{Endurance testing}

The ventilator was set to $V_{T}=330 \mathrm{~mL}$, inspiratory time $=1.0 \mathrm{~s}$, and con-

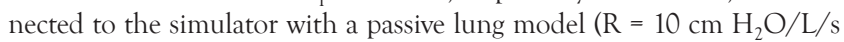
and $\mathrm{C}=40 \mathrm{~mL} / \mathrm{cm} \mathrm{H}_{2} \mathrm{O}$ ) and left to run uninterrupted for $48 \mathrm{~h}$. Pressure, volume, and flow waveforms were recorded by the simulator. Values for delivered tidal volume and waveforms from the start and end of the testing period were compared for consistency.

Accuracy of $\mathrm{FiO}_{2}$ setting

To determine the accuracy of the $\mathrm{FiO}_{2}$ setting using the air and oxygen flowmeters, the flowmeters were varied in increments of $5 \mathrm{~L} / \mathrm{min}$ throughout their calibrated range for all combinations of air and oxygen flow. The achieved $\mathrm{FiO}_{2}$ was measured using a $\mathrm{MaxO} 2 \mathrm{ME}$ oxygen monitor with Max 550E oxygen sensor (Maxtec, Salt Lake City, UT). All measurements were performed in triplicate. The measured values were compared with the expected values assuming $21 \% \mathrm{O}_{2}$ concentration in air and $100 \% \mathrm{O}_{2}$ from medical oxygen supply.

Accuracy of built-in pressure sensor PEEP and PIP calculations While conducting performance characterization of the ventilator, the ventilator-calculated PEEP and PIP readings were recorded and compared to the values measured by the simulator to assess the accuracy of the built-in ventilator pressure sensor.

Ventilator settings for comparison to commercial ventilator The prototype ventilator delivers only one mode of assisted ventilation, VC-IMV (i.e., mandatory breaths not synchronized to patient effort). To compare its performance to a commercial ventilator, we selected the Puritan Bennet PB840 with the trigger threshold set to maximum, making the mode effectively VC-IMV (square flow waveform selected) instead of VC-SIMV. An anesthesia circuit without a humidifier was used. The ventilator was initialized per manufacturer instructions and compensation for circuit compliance was turned on. The compliance for said circuit was noted by the ventilator to be $2.44 \mathrm{~mL} / \mathrm{cm} \mathrm{H}_{2} \mathrm{O}$.

Both ventilators were set with parameters representative of ventilation for a typical ARDS patient: $\mathrm{V}_{\mathrm{T}}=500 \mathrm{~mL}$, peak flow at $30 \mathrm{~L} / \mathrm{min}$ with a square waveform to utilize an inspiratory time $=1 \mathrm{~s}$, and breath rate $=$ $18 / \mathrm{min}$. The $\mathrm{FiO}_{2}$ was irrelevant for this experiment so it was set at 0.21 .

The prototype ventilator was set to $30 \mathrm{~L} / \mathrm{min}$ from the wall, and $\mathrm{T}_{\mathrm{I}}$ was set to $1 \mathrm{~s}$. PEEP for both ventilators was set to $5 \mathrm{~cm} \mathrm{H}_{2} \mathrm{O}$.

Pressure, volume, and flow waveforms were recorded by the simulator.

\section{Performance characterization}

\section{RESULTS}

The prototype ventilator was set to various flow and inspiratory-time combinations to deliver varying tidal volumes. The simulator measured PIP and PEEP values were within $10 \%$ of those recorded by the prototype ventilator (Figures 4a, 4b).

Hospital $\mathrm{O}_{2}$ and medical air flow meters were set to expected $\mathrm{FiO}_{2}$ values from $21 \%$ to $100 \%$ per previously discussed nomograms (Supplemental Figure $2^{1}$ ). $\mathrm{FiO}_{2}$ was measured at the end of the patient circuit and compared to expected values, falling within $2 \%$ of the desired value for all settings required for ventilation (Supplemental Figure $4^{1}$ ).

The set tidal volume on the prototype ventilator was calculated per the formula below.

Set $\mathrm{V}_{\mathrm{T}}(\mathrm{mL})=$ Inspiratory Flow $(\mathrm{L} / \mathrm{min}) \times \mathrm{T}_{\mathrm{I}}(\mathrm{s}) \times(1000 / 60)$

Accounting for compressed tidal volume caused the calculated tidal volume to always be lower than set. Under ATPD conditions, the tidal volume was closer to this calculated value, whereas under BTPS conditions, in which the gas would normally expand due to the higher temperature, the measured tidal volume was closer to the set tidal volume (Figure 4c).

In the simulated changing compliance model, the prototype ventilator maintained tidal volumes, PEEP, breath rate, peak inspiratory flow

\section{FIGURE 4}

Performance characterization. PIP measured on the simulator are within $10 \%$ of the readings obtained off the prototype ventilator. (a) PEEP measurements using the simulator are within $10 \%$ of the readings obtained from the prototype ventilator. (b) Tidal volume (VT) measurements under ATPD conditions and BTPS conditions VT.

\section{a.}

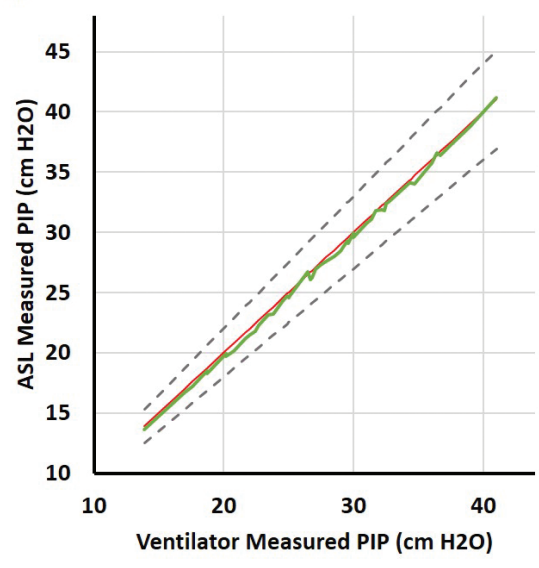

b. Positive End-Expiratory Pressure (PEEP)

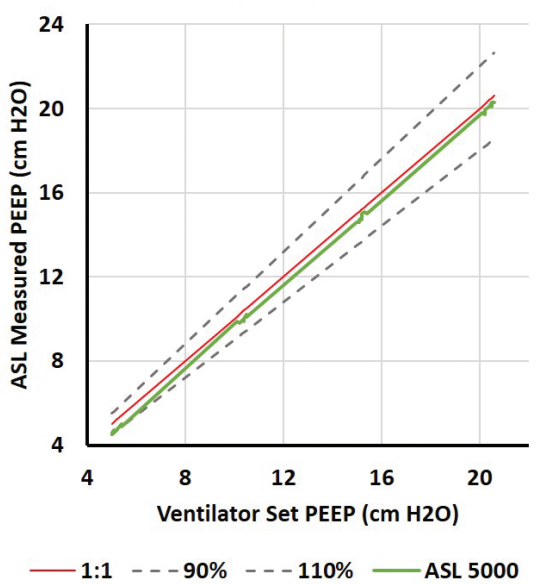

c.

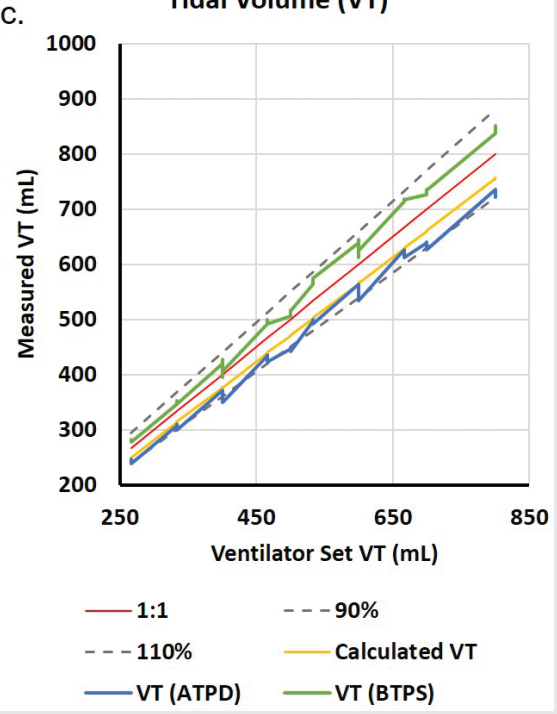


rate, and $\mathrm{T}_{\mathrm{I}}$ within $10 \%$ of baseline despite a $60 \%$ decrease in compliance and a more than $50 \%$ increase in peak pressures (Figure 5).

\section{Endurance testing}

The ventilator was left to run for $48 \mathrm{~h}$, demonstrating reliable function for $>58,000$ cycles without interruption. With goal $\mathrm{V}_{\mathrm{T}}=330 \mathrm{~mL}$, measured $\mathrm{V}_{\mathrm{T}}$ a $\mathrm{T}=48 \mathrm{~h}$ was $333.6 \mathrm{~mL}$ compared with $339.3 \mathrm{~mL}$ at $\mathrm{T}=0 \mathrm{~h}$, resulting in a change of $-1.6 \%$.

\section{Comparison to commercial ventilator}

Using BTPS tidal volumes and the passive breath model, the prototype ventilator was noted to be able to deliver tidal volumes to within $10 \%$ of what was set. This was like the performance of the commercial ventilator tested (Figures 6a, 6b). Of note, the commercial ventilator did overshoot the set tidal volume target but remained within $10 \%$.

Using the passive breath model and 60 consecutive breaths, the prototype ventilator was noted to deliver similar PEEP levels to a commercial ventilator when both were set to a PEEP of $5 \mathrm{~cm} \mathrm{H}_{2} \mathrm{O}$ (Figure 6c). Delivered PIP was similar, albeit the prototype ventilator generated lower PIP as the tidal volumes were lower than those delivered by the commercial ventilator (Figure 6d).

Both the prototype and the commercial ventilators generated similar square-wave flow waveforms, similar tidal volume waveforms, and pressure waveforms. When a spontaneous effort (Pmus) coincided with a mandatory breath, both ventilators experienced a similar distortion of the pressure waveforms. Interestingly, our prototype ventilator did not experience as deep of a dip in PEEP when a spontaneous effort occurred in between mandatory breaths. This was accompanied by a more pronounced rise in flow during that spontaneous breath (Figures $7 \mathrm{a}-7 \mathrm{c}$ ).

The conclusions from the performance evaluation are summarized in Table 3.

\section{DISCUSSION}

The emerging COVID-19 pandemic has led to a widespread shortage of intensive care unit (ICU) beds, ventilators, and trained operators, resulting in an effort to provide respiratory support and ventilation to patients by a number of alternative means. To ration ventilators, hospitals have increased usage of nontraditional methods of ventilating patients, including repurposing noninvasive positive pressure ventilators (NIPPV) [21]. and using multiplex ventilation to ventilate multiple patients with a single ventilator. Each of these modalities carries significant limitations. NIPPV fails to provide a secure airway and cannot provide high levels of PEEP. Multiplex ventilation, as currently described, does not allow for patient-specific regulation of parameters such as $\mathrm{FiO}_{2}$, tidal volume, and PEEP, and it has universally been discouraged $[9,10,22]$.

The past shortage of ventilators and experienced operators accompanied a growing recognition that many stockpile ventilators were inoperable due to maintenance issues, suggesting a need for a dedicated emergency stockpile ventilator that is cheap, reliable, and simple to use. Our ventilator was designed with cost, design simplicity, durability, and ease of use by inexperienced providers in mind.

Most existing ventilator models are expensive and run from US $\$ 10,000$ to US $\$ 50,000$. In cases where hundreds or thousands of ventilators are needed, these costs can be prohibitive [23]. Efforts to provide a low-cost emergency ventilator have led to several design concepts relevant to this discussion. One frequently proposed type of device utilizes BVM ventilation, but it replaces manual operation of the BVM with a mechanical actuator that is electronically controlled. This idea has been previously described [7], and has been disseminated in multiple formats on open source platforms. The advantages of using mechanical BVM systems as a ventilator include low cost, rapid scalability, and conceptually easy use. A major limitation of BVM-based designs lies in the inability to finely control flow rates and inspiratory times, impacting both pressure and volume delivery during inspiration. Air bladder

\section{FIGURE 5}

Ventilator behavior with changing compliance. The prototype ventilator maintains tidal volume delivery, PEEP, breath rate, PIFR, Mean Flow, and I-time within $10 \%$ from baseline despite incremental reductions in compliance and rise peak inspiratory pressures.

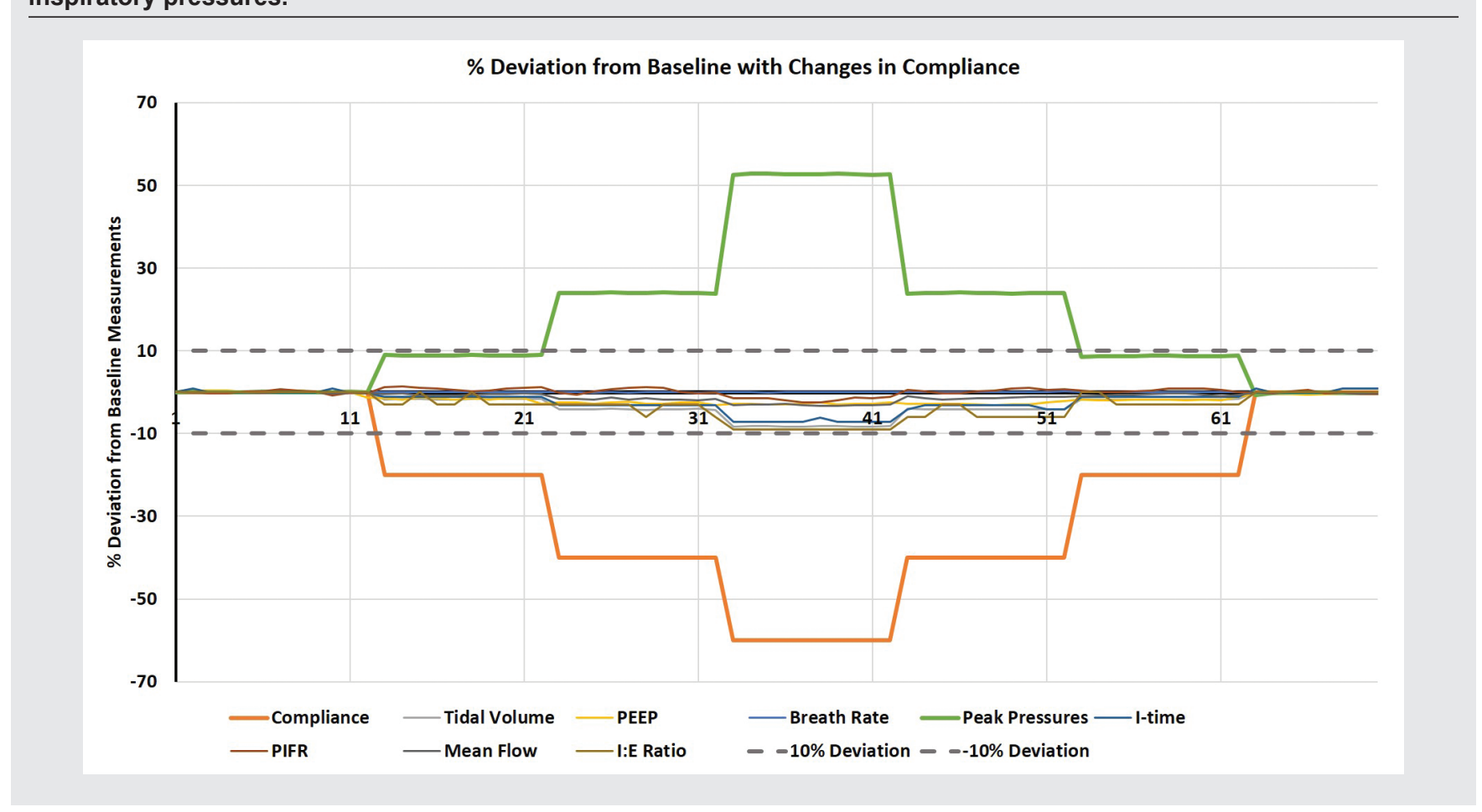




\section{FIGURE 6}

Commercial ventilator 60 breath comparison. The prototype \& commercial ventilators are both within $10 \%$ deviation from the set $500 \mathrm{~mL}$ tidal volume under BTPS conditions. (a) The prototype and commercial ventilators generate similar amounts of peak inspiratory flow rates under BTPS conditions. (b) The prototype $\&$ commercial ventilators are both within a $10 \%$ deviation from the set PEEP of $5 \mathrm{~cm} \mathrm{H}$ O. (c) The prototype and commercial ventilators generate similar peak inspiratory pressures to deliver their set tidal volumes.

a.

Tidal Volume (BTPS)

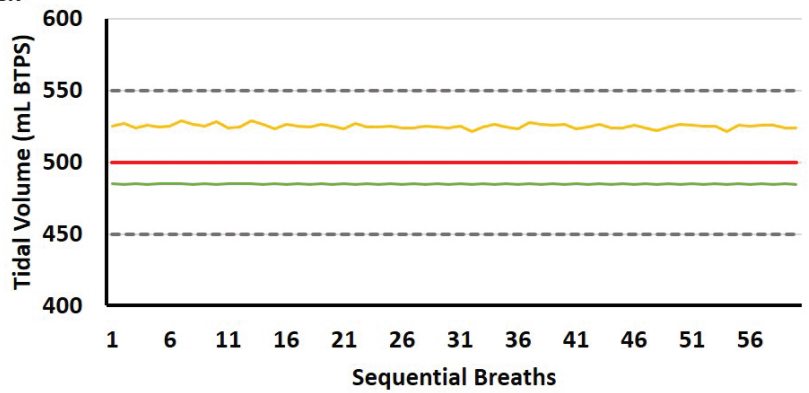

PEEP (BTPS)

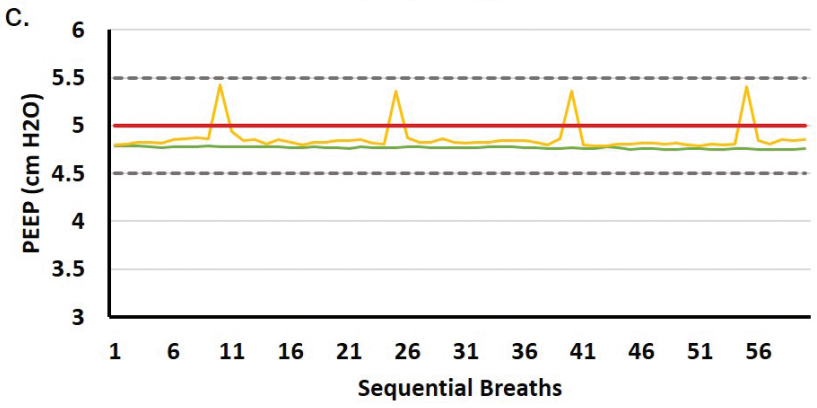

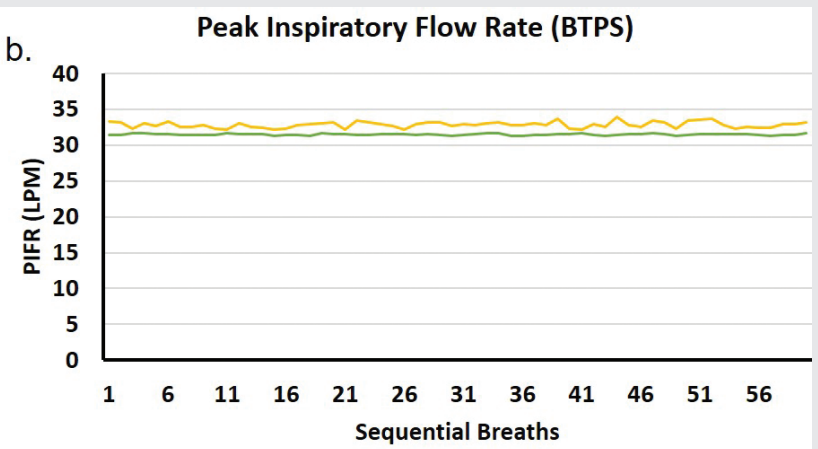

d.

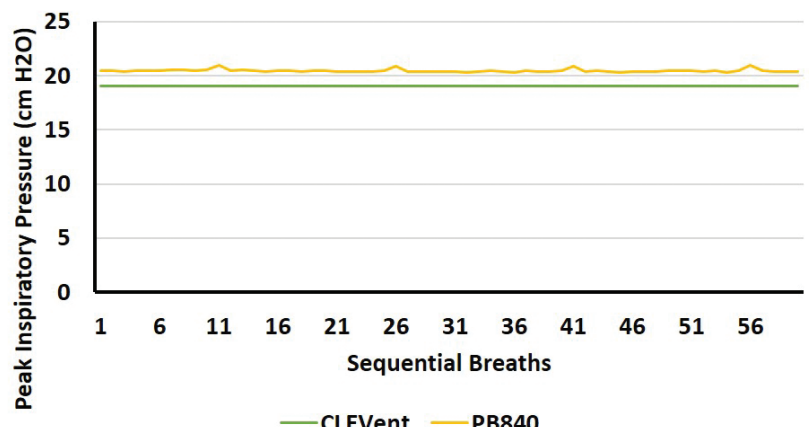

durability is also a concern, as these devices were never designed to provide ventilation for long periods of time and, to our knowledge, have not been extensively testing in this regard. For these reasons, emergency ventilators that rely on this design may be best used as a temporary method of ventilation in a field hospital or low-resource setting.

Another low-cost design utilizes water columns to regulate PIP and PEEP from a high-pressure medical gas (oxygen and air) source [8]. While this design can provide the proper volumes and pressures required for support of a patient with ARDS, the use of water columns to regulate pressure may be difficult to integrate into a usable device, it requires calibration with each use, and it can be difficult to manipulate during operation.

Since initial shortages, the stock of ventilators in the United States and other developed countries has rapidly increased. This is in part because many companies are contributing manufacturing resources towards the production of thousands of ventilators, a notable example being the partnership between Ford, General Motors and GE Healthcare [24] Though the overall need for invasive ventilation has fallen from a peak in mid-April 2020, projections estimate a return to this level of demand in the US by December 2020 in the form of a second wave [25].

At a material components cost of under $\$ 500$ per unit, production of our device is affordable on a large scale. This is further supported by using widely available parts. Apart from the enclosure, the parts were easily found and sourced from online retailers. Pneumatic valves were also easily sourced in this circumstance and could be found online or at local distributors. Basing the design on external air and oxygen flow meters, our ventilator could be widely adopted in hospitals with $50 \mathrm{psi}$ gas sources, both in existing ICU rooms, and on other nursing floors.
Our device is also robust. We have demonstrated reliable delivery of desired tidal volumes across a wide range of ventilation parameters, with an observed error of less than $10 \%$. We were able to consistently manipulate breath rate, inspiratory time, flow rate, and PEEP across the range of possible values needed for implementation in the clinical environment, while maintaining limits on pressure and volume to ensure safety of use. Our testing suggests the performance of this device is comparable to current, mainstream commercial ventilators.

Another advantage of our device is the simplicity of design and use. We feature a single volume control mode with limited inputs to ensure orientation and training on the device is efficient for the inexperienced user. This simple design limits potential sources of error that could easily occur in the hands of an inexperienced provider using a more complex ventilator. We feel that this is crucial to the operation of a simple ventilator in the emergency setting, given disparities in clinical education and experience when non-ICU providers and support staff are called to assist in intensive care efforts. Safety in this device is further supported by integrated electronic and pneumatic safety valve features that limit the maximum pressure applied to the airway to prevent lung injury in the event of malfunction or misuse. Other safety features include a disconnect alarm and a power-loss alarm, which are necessary components of any mechanical ventilator. Due to the design of the inspiratory system, with continuous airflow provided from hospital air and oxygen supplies, there is sufficient bias flow in the system to allow for patient inspiration in the event of power failure. Future safety iterations may integrate an $\mathrm{O}_{2}$ analyzer for real-time $\mathrm{FiO}_{2}$ monitoring and back-up ventilation features in the event of building power loss, though requiring a battery back-up may complicate utilization as a stockpile ventilator due to maintenance 


\section{FIGURE 7}

Commercial ventilator waveforms. (a) Square flow waveforms. Red arrows reflect spontaneous efforts during IMV. Black arrows indicate flow during these efforts, which is higher in the prototype ventilator. (b) Tidal volume waveforms. Red arrows show spontaneous efforts during IMV breaths. Black arrows show larger tidal volume generation between IMV breaths in the prototype ventilator. (c) Pressure waveforms. Red arrows show distortion of the waveform under effect of Pmus. Black arrows show PEEP changes after spontaneous effort between IMV breaths, which are less in the prototype ventilator.
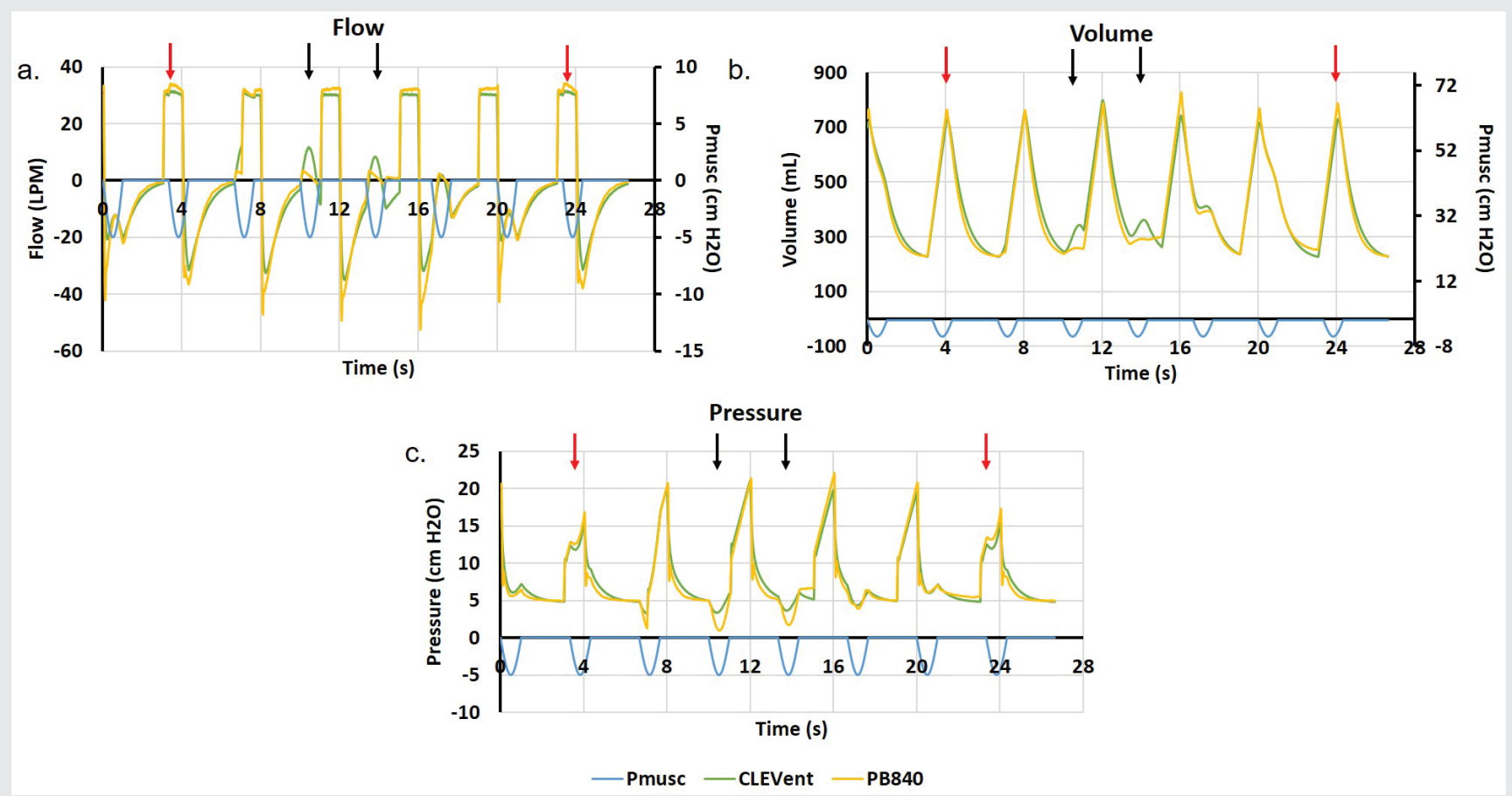

\section{TABLE 3}

\section{Summary of performance evaluation experiments}

- The prototype ventilator delivers tidal volumes \& peak inspiratory flow rates similar to a commercial ventilator.

- The prototype ventilator delivers similar peep and peak inspiratory pressures similar to a commercial ventilator.

- The prototype ventilator provides similar support to a commercial ventilator during active breathing.

requirements. The problem of limited shelf-life of backup batteries may be overcome by using commercially available uninterruptable power supplies or device design allowing for readily available, off-the-shelf batteries to serve as backup power.

Our device has limitations inherent to intentional reliance on readily available utilities in the hospital. Given the dependence on compressed air and $\mathrm{O}_{2}$, our device would not be able to operate outside of a traditional hospital in its current form. Conceptually, portable air and $\mathrm{O}_{2}$ tanks could be used, or an air blower and/or oxygen concentrator could be added to the design. Because our design assumptions indicated that medical gas supplies would be available, we did not add blower capabilities. There may also be a limit on attainable values of $\mathrm{FiO}_{2}$, depending on the availability of $\mathrm{O}_{2}$ flowmeters and appropriate $\mathrm{O}_{2}$ fittings in the hospital. Given the traditional hospital flowmeter delivers a maximum of $15 \mathrm{~L} / \mathrm{min}$, additional flowmeters would have to be added and joined to the common $\mathrm{O}_{2}$ input on the device via hosing and a splitter with appropriate $\mathrm{O}_{2}$ fittings if high tidal volumes $(>500 \mathrm{~mL})$ and $100 \% \mathrm{FiO}_{2}$ are desired. Another limitation is the use of a battery for the alarm system. Stockpiled ventilators may not have adequate battery maintenance. One solution might be to replace the battery with a high-volume capacitor that would be charged during ventilator operation and provide enough discharge current for short-term alarm operation. Limiting cost and complexity presents many inherent limitations to our prototype. Designing around a single limb circuit allows for a less complex device, but it precludes the ability to monitor expiratory flow. Our device also does not have the capability to display waveforms in real time on the front panel, though this could be done by integrating a larger LCD or OLED screen and more complex software changes. Our device also does not have an electronic sensor for flow, rather relying on manual inputs to hospital flowmeters. An integrated electronic flowmeter would address this limitation and could provide clinically useful information to display as waveform data on a future iteration of our device, as well as integrate further safety and alarm features into the device.

We plan to continue developing, testing, and optimizing this prototype. Future steps include formal testing for ease of use with respiratory therapists and other clinicians, and integration with a rolling stand for improved clinical utility. The design may also be adapted for related uses, including a neonatal device application and alterations for use in developing countries.

\section{CONCLUSIONS}

In response to the emerging COVID-19 pandemic, our team was able to design, build, test, and validate a low-cost emergency ventilator suitable to the needs of a stockpile type ventilator. This device delivers volume control ventilation via a simple design with user inputs of inspiratory time, flow rate, PEEP, and breath rate. Despite its low cost, essential 
safety features are built into the device, making it safe and easy to use for a broad range of health care personnel.

\section{DISCLOSURES AND ACKNOWLEDGMENTS}

Competing interests: All authors have completed the ICMJE uniform disclosure form at www.icmje.org/coi_disclosure.pdf and declare: no financial relationships with any organizations that might have an interest in the submitted work in the previous 3 years; no other relationships or activities that could appear to have influenced the submitted work.

\section{REFERENCES}

1. World Health Organization. Coronavirus disease 2019 (COVID-19) Situation report - 202. 2020:1-16. Available at: https://www.who.int/ docs/default-source/coronaviruse/situation-reports/20200809-covid-19-sitrep-202.pdf?sfursn=2c7459f6_2 (Accessed August 10, 2020).

2. Zhou F, Yu T, Du R, et al. Clinical course and risk factors for mortality of adult inpatients with COVID-19 in Wuhan, China: a retrospective cohort study. Lancet. 2020;395(10229):1054-62. doi: 10.1016/S01406736(20)30566-3.

3. Wu C, Chen X, Cai Y, et al. Risk factors associated with acute respiratory distress syndrome and death in patients with coronavirus disease 2019 pneumonia in Wuhan, China. JAMA Int Med 2020:180(7):934-43. doi: 10.1001/jamainternmed.2020.0994.

4. Guan W-J, Ni Z-Y, Hu Y, et al. Clinical characteristics of coronavirus disease 2019 in China. N Engl J Med 2020;382(18):1708-20. doi: 10.1056/NEJMoa2002032.

5. Chanaka N, Kahathuduwa CSDS-HC. Case fatality rate in COVID-19: a systematic review and meta-analysis. MedRXiV 2020.04.01.20050476 2020:1-45. doi: 10.1101/2020.04.01.20050476.

6. White DB, Lo B. A framework for rationing ventilators and critical care beds during the COVID-19 pandemic. JAMA 2020;323(18):1773-4. doi: 10.1001/jama.2020.5046.

7. Mohsen Al Husseini A, Ju Lee H, Negrete J, Powelson S, Tepper Servi A, Slocum AH. Design and prototyping of a low-cost portable mechanical ventilator.J Med DevTrans ASME 2010;4(2):1-1.doi: 10.1115/1.3442790.

8. Galbiati C, Bonivento W, Caravati M, et al. Mechanical Ventilator Milano (MVM): a novel mechanical ventilator designed for mass scale production in response to the COVID-19 pandemics. aRXiV PREPRINT 2020;2003(10405):1-8.

9. Chatburn RL, Branson RD, Hatipoğlu U. Multiplex ventilation: a simulation-based study of ventilating two patients with one ventilator. Respir Care 2020;65(5):1-12. doi: 10.4187/respcare.07882.

10. American Association for Respiratory Care. Joint statement on multiple patients per ventilator. March, 2020. American Association for Respiratory Care, Irving, TX. Available at https://www.aarc.org/wp-content/uploads/2020/03/032620-COVID-19-press-release.pdf.

11. Bhatraju PK, Ghassemieh BJ, Nichols M, et al. Covid-19 in critically ill patients in the Seattle Region - case series. N Engl J Med 2020:382(21): 2012-22. doi: 10.1056/NEJMoa2004500.
12. American Association for Respiratory Care Protocol Committee. Subcommittee adult critical care version a. Adult Mechanical Ventilator Protocols, September, 2003. American Association for Respiratory Care, Irving, TX.

13. United Kingdom MHRA. Rapidly manufactured ventilator system. 2020. p. 1-25. Medicines \& Healthcare products Regulatory Agency; United Kingdom. London, United Kingdom. Published 20 March 2020. Available at: https://assets.publishing.service.gov.uk/government/ uploads/system/uploads/attachment_data/file/879382/ RMVS001_v4.pdf

14. Association for the Advancement of Medical Instrumentation consensus report: emergency use ventilator (EUV) design guidance. AAMI/CR501: 2020. Association for the Advancement of Medical Instrumentation, Arlington, VA. Available at: https://www.aami.org/docs/default-source/ standardslibrary/200410_cr501-2020_rev1-2.pdf?sfvrsn=699e62b7_2 (Accessed April 8, 2020).

15. Mireles-Cabodevila E, Hatipoğlu U, Chatburn RL. A rational framework for selecting modes of ventilation. Respir Care 2013;58(2):348-66. doi: 10.4187/respcare.01839

16. World Health Organization. (2020). Clinical management of severe acute respiratory infection (SARI) when COVID-19 disease is suspected: interim guidance, World Health Organization. https://apps. who.int/iris/handle/10665/331446 (Accessed March 13, 2020).

17. Chatburn RL, El-Khatib M, Mireles-Cabodevila E. A taxonomy for mechanical ventilation: 10 fundamental maxims. Respir Care 2014;59(11):1747-63. doi: 10.4187/respcare.03057

18. Sanborn WG. Microprocessor-based mechanical ventilation. Respir Care 1993;38(1):72-109.

19. Chatburn RL, Mireles-Cabodevila E. 2019 year in review: patient-ventilator synchrony. Respir Care 2020;65(4):558-72. doi: 10.4187/respcare.07635

20. Arnal JM, Garnero A, Saoli M, Chatburn RL. Parameters for simulation of adult subjects during mechanical ventilation. Respir Care 2018;63(2): 158-68. doi: $10.4187 /$ respcare. 05775

21. Namendys-Silva SA, Hernández-Garay M, Rivero-Sigarroa E. Non-invasive ventilation for critically ill patients with pandemic H1N1 2009 influenza A virus infection. Crit Care 2010;14(2):407. doi: 10.1186/cc8883

22. Branson RD, Blakeman TC, Robinson BRH, Johannigman JA. Use of a single ventilator to support 4 patients: laboratory evaluation of a limited concept. Respir Care 2012;57(3):399-403. doi: 10.4187/respcare. 01236

23. Rowland C. More lifesaving ventilators are available. Hospitals can't afford them. Available at: https://www.washingtonpost.com/health/2020/03/18/ ventilator-shortage-hospital-icu-coronavirus/ (Accessed March 18, 2020).

24. Albergotti R, Siddiqui F. Ford and GM are undertaking a warlike effort to produce ventilators. It may fall short and come too late. Available at: https://www.washingtonpost.com/business/2020/04/04/ventilators-coronavirus-ford-gm/ (Accessed April 4, 2020).

25. University of Washington Institute for Health Metrics and Evaluation. Hospital resource use. Available at: https://covid19.healthdata.org/united-states-of-america (Accessed August 11, 2020). 